\title{
Bilateral Carotid Aneurysms Secondary to Catastrophic Antiphospholipid Syndrome in a Patient with Differential Diagnosis of Polyarteritis Nodosa
}

\author{
Alexandre Sacchetti Bezerra ${ }^{1^{*}}\left(\mathbb{D}\right.$, Fernanda Gonçalves Moya $^{2}\left(\mathbb{C}^{\circ}\right.$, \\ Idalecio Souto Fonseca Filho ${ }^{3}\left({ }^{\circ}\right.$, Alexandre Cesar Fioretti ${ }^{3}$ \\ ${ }^{1}$ Instituto de Infectologia Emilio Ribas, São Paulo, Brazil \\ ${ }^{2}$ Universidade de Sao Paulo, São Paulo, Brazil \\ ${ }^{3}$ Faculdade de Medicina do ABC, São Paulo, Brazil \\ Email:*a.bezerr@uol.com.br
}

How to cite this paper: Bezerra, A.S., Moya, F.G., Filho, I.S.F. and Fioretti, A.C. (2022) Bilateral Carotid Aneurysms Secondary to Catastrophic Antiphospholipid Syndrome in a Patient with Differential Diagnosis of Polyarteritis Nodosa. World Journal of Cardiovascular Diseases, 12, 30-37.

https://doi.org/10.4236/wjcd.2022.121004

Received: December 16, 2021

Accepted: January 22, 2022

Published: January 25, 2022

Copyright $\odot 2022$ by author(s) and Scientific Research Publishing Inc. This work is licensed under the Creative Commons Attribution International License (CC BY 4.0).

http://creativecommons.org/licenses/by/4.0/ (c) (i) Open Access

\begin{abstract}
Background: Extracranial Carotid Artery Aneurysm is considered a therapeutic and diagnostic challenge. In an unprecedented way in the literature, we describe an aneurysm originating from the Catastrophic Antiphospholipid Syndrome. Case Presentation: A 25-year-old male patient came to the Emergency Room of the ABC University Hospital in Sao Bernardo do Campo referring to bilateral neck pain for 1 month, associated with carotid aneurysms. Due to the severity and urgency of the clinical condition, immediate surgical therapy was performed without a definitive etiological diagnosis. The initial morphological analysis of the carotid artery suggested a diagnosis of Polyarteritis Nodosa. After anamnesis, physical examination, the use of a specific primary vasculitis algorithm, and a review of the pathological anatomy was requested, which showed bilateral carotid aneurysms secondary to catastrophic antiphospholipid syndrome. Conclusion: It remains evident that Extracranial Carotid Artery Aneurysm-related morbidity and mortality caused by Catastrophic Antiphospholipid Syndrome are influenced by a quick and correct diagnosis.
\end{abstract}

\section{Keywords}

Aneurism, Anticardiolipin Antibodies, Antiphospholipid Syndrome, Carotid Artery, Thrombosis

\section{Introduction}

More than a decade ago, El-sabrout et al. defined Extracranial Carotid Artery 
Aneurysm (ECAA) as a diagnostic and therapeutic challenge [1].

Acknowledged for its rarity, the ECAA has a wide range of signs and symptoms ranging from neck pain to neurological changes, which makes the etiological diagnosis difficult (Table 1).

Although there is no consensus in the literature, some authors classify the lesion before treating (Table 2). In most reviews, open repair of these injuries is recommended [2] [3].

The present report describes the clinical case of a young man who presented type IV secondary carotid vasculopathy resulting from thrombophilia.

Scientific articles referring to the ECAA describe long-term casuistry. Reviews are thorough showing risks, prognosis and possible surgical complications. Despite this large amount of information, we did not find an ECAA caused by Catastrophic Antiphospholipid Syndrome (CAPS) in the literature.

\section{Case Presentation}

A 25-year-old male patient came to the Emergency Room of the University Hospital in Sao Bernardo do Campo referring bilateral neck pain for 01 month, associated with carotid tumors.

Table 1. ECAA etiological diagnosis.

\begin{tabular}{l}
\hline ECAA etiological diagnosis \\
\hline Primary vasculitis \\
Atherosclerosis \\
Fibromuscular dysplasia \\
Thrombophilia \\
Cystic medial necrosis \\
Connective tissue disease \\
Loeys-Dietz syndrome \\
Marfan syndrome \\
Ehlers-Danlos syndrome \\
Elastic pseudoxanthomas \\
Tuberous sclerosis \\
\hline
\end{tabular}

Table 2. ECAA classification.

\section{ECAA classification}

Type I: Isolated aneurysms of the internal carotid artery

Type II: Aneurysms of the complete internal carotid artery with involvement of the bifurcation

Type III: Aneurysms of the carotid bifurcation

Type IV: Combined aneurysm of the internal and common carotid artery

Type V: Isolated aneurysm of the common carotid artery 
During propaedeutic investigation, he reported clinical treatment (05 $\mathrm{mg}$ of warfarin/day for 5 years) of antiphospholipid syndrome (APS) with bilateral lower limb thrombosis, sagittal sinus and portal system (esophageal varices).

Cervical computed tomographic angiography showed left and right saccular aneurysmal dilatation (Figure 1).

An open surgical approach to the left was performed due to extrinsic compression of adjacent structures and angulation between the common and internal carotid artery, which was inappropriate for endovascular correction.

Surgical procedure took place under general anesthesia, with a wide left cervicotomy. An aneurysmal lesion with an important inflammatory process was identified (Figure 2).

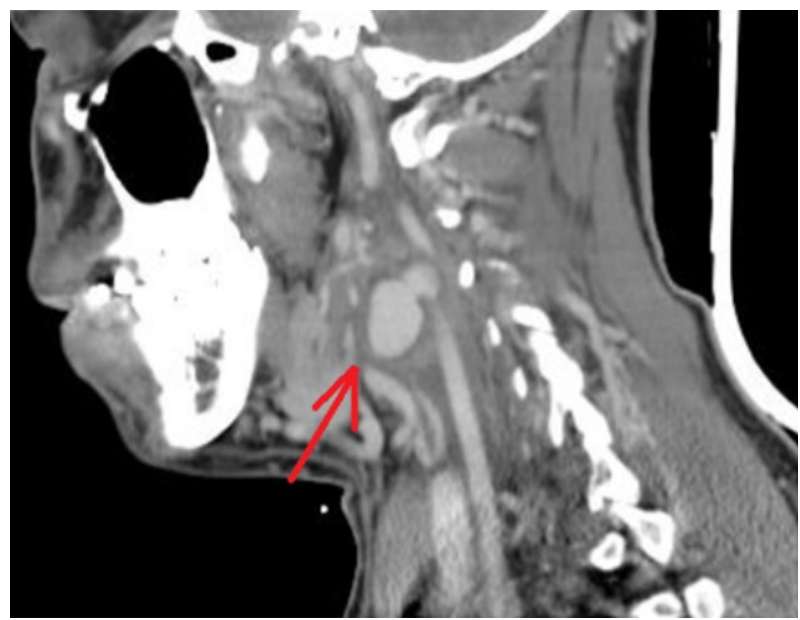

Figure 1. Cervical computed tomographic angiography.

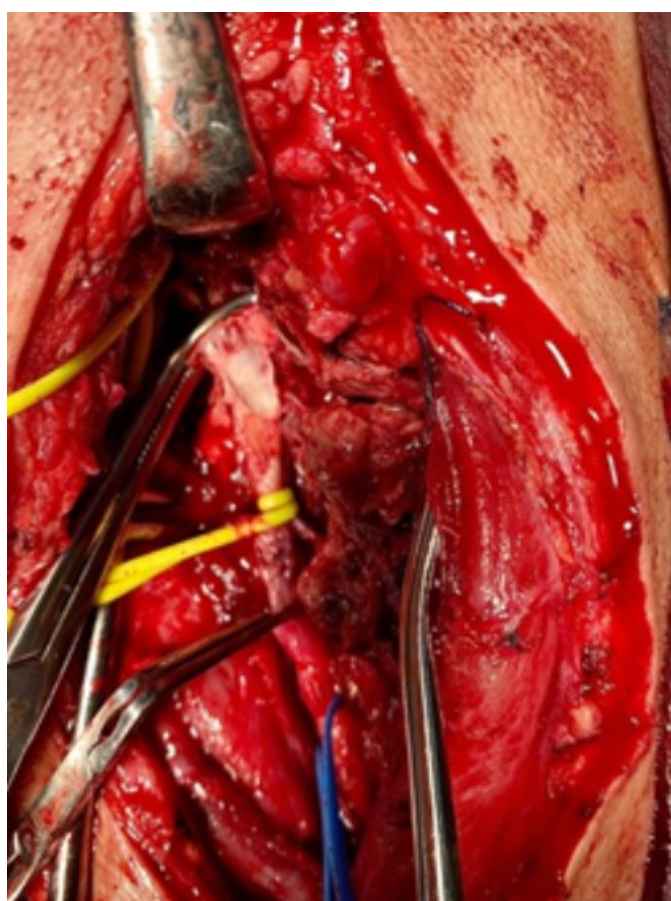

Figure 2. Surgical procedure. 
In the postoperative period, the patient had good recovery, evolving without neurological deficit and with persistent pain in the right topography (without surgery side). After 12 days, the right carotid artery was revascularized.

Four days after the second surgery (right site), the patient was discharged home, died within 18 weeks of high digestive hemorrhage resulting from esophageal varices.

The initial pathological study described a possible "fibrinoid necrosis with neutronphilic infiltrate in the vessel wall, without formation of granulomas, suggesting necrotizing vasculitis compatible with Polyarteritis Nodosa (PAN)".

The careful analysis of clinical data does not allow the use of the Bezerra algorithm in Primary Vasculitis, which required a thorough review of the pathological study, as documented in Figure 3 and Figure 4.

In both, no PAN characteristics were observed. Figure 3 and Figure 4 do not show transmural necrotizing inflammation of medium and small caliber arteries.

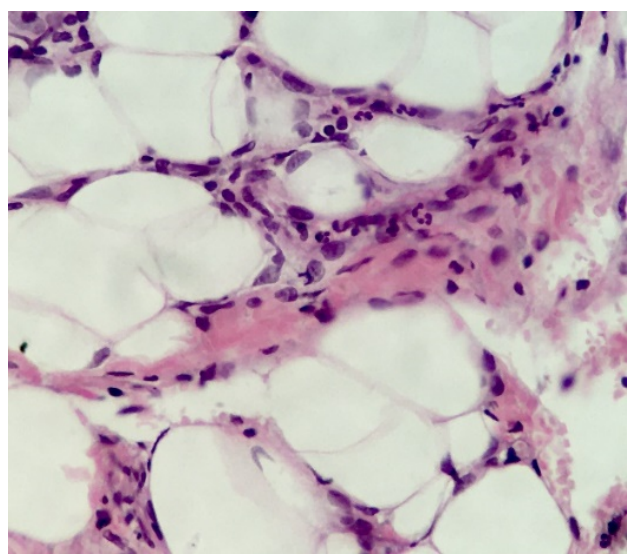

Figure 3. Haematoxylin and eosin-stained section from cervical peri-lymphonodal adipose tissue showing fibrin trombi in small vessels and sparse neutrophils (original magnification $\times 40)$.

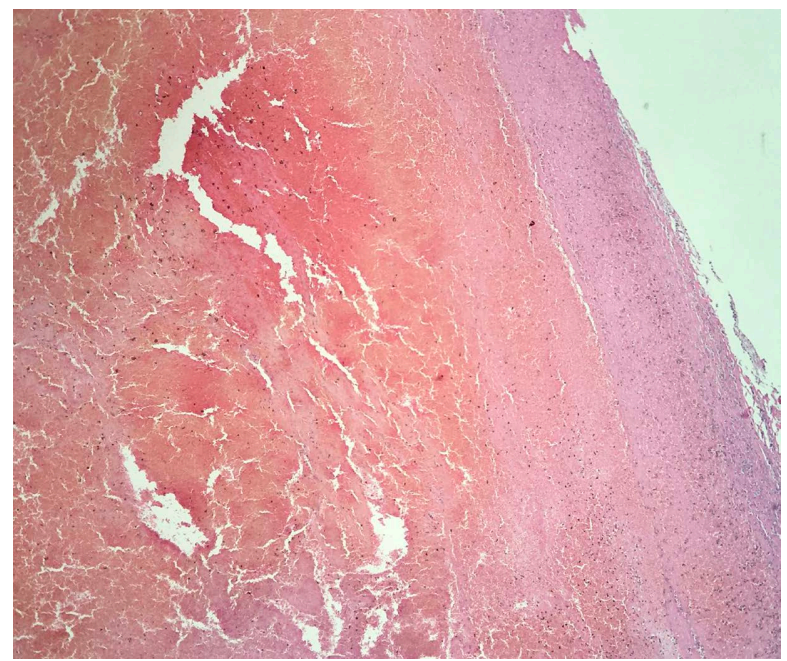

Figure 4. Haematoxylin and eosin-stained section from left carotid artery showing aneurysm with degeneration, necrosis and intraluminal thrombus (original magnification $\times 10$ ). 


\section{Discussion}

In the etiological research of ECAA, there are numerous differential diagnoses, as shown in Table 1, among which primary vasculitis and thrombophilias stand out.

In the study of primary vasculitis, despite the Bezerra algorithm and the 2013 International Chapel Hill Consensus (CHCC) do not present eligible criteria for the diagnosis of PAN, was tried to use the traditional criteria of the 1994 International Chapel Hill Consensus (CHCC) in which the patient must present 3 or more of the ten criteria in Table 3, making the sensitivity of $82 \%$ and specificity of $87 \%$ [4] [5].

In 1994, CHCC criteria there were also no positive diagnosis of PAN [6].

During anamnesis, the patient was referred to a treatment for APS that can be classified as thrombotic (TAPS), obstetric (OAPS) and catastrophic (CAPS). This classification allows patients to be stratified in order to intensify therapy in those with greater morbidity, as is the case with CAPS [7] [8] [9] [10] [11].

Due to the obligatory nature of the four criteria listed in Table 4, CAPS becomes rare, affecting less than 1.0\% of patients with APS [8] [10] [11] [12] [13].

Retrospective analysis showed later that the patient met the four criteria in Table 4, confirming the diagnosis of CAPS.

Due to the high recurrence of thrombotic events in CAPS, anticoagulation should be perennial [11] [14] [15].

The use of glucocorticoids in CAPS can be performed with 0.5 to $1.0 \mathrm{~g} /$ day for 3 days. After the third day, oral prednisone was substituted with $1 \mathrm{mg} / \mathrm{kg} / \mathrm{day}$. The patient in question did not use prednisone [8] [15].

Table 3. The Chapel Hill Consensus Conference (CHCC) criteria por Polyarteritis Nodosa symptom.

The Chapel Hill Consensus Conference (CHCC) Criteria for Polyarteritis Nodosa Symptom

Unexplainable Weight Loss of More than $4 \mathrm{~kg}$

Testicular Pain or Tenderness

Myalgias/Muscle Weakness

Mononeuropathy or Polyneuropathy

Elevated Levels of Serum Urea Nitrogen $(>40 \mathrm{mg} / \mathrm{dl}$ or $14.3 \mathrm{mmol} / \mathrm{l})$ or Creatinine $(>1.5$ $\mathrm{mg} / \mathrm{dl}$ or $132 \mathrm{mmol} / \mathrm{l}$ )

Evidence of Hepatitis B Virus Infection by Serum Antibodies or Antigen Serology (Old Concept)

Characteristic Arteriographic Abnormalities Not Resulting from Non-Inflammatory Disease Processes

Small or Medium Artery Biopsy Containing Polymorphonuclear Cells

Recent Start Diastolic Blood Pressure over 90 mmHg

Livedo Reticularis 
Table 4. Mandatory diagnostic criteria in CAPS.

\section{Mandatory diagnostic criteria in CAPS}

1. Clinical manifestations in different anatomical sites in less than 01 week

2. Involvement of three or more organs or tissues

3. Biopsy with histopathological analysis showing small vessel affection (stasis/thrombosis/angiogenesis)

4. Laboratory changes with anti antiphospholipid antibodies

- Anticardiolipin (AC)

- Lupus anticoagulant (AL)

- Anti-beta-2-glycoprotein I (anti B2-GPI)

- Laboratory confirmation 12 weeks after the first collection

There is no consensus in the literature about the use of plasmapheresis in patients with CAPS [8] [11] [14] [16].

There were no randomized studies about Intravenous Immunoglobulin (IVIG) that allow their use. IVIG was not used in this case [8] [14].

Refractory cases of CAPS can benefit from the use of antiplatelet agents and immunomodulators such as chloroquine [11] [14] [17].

Monoclonal antibodies anti-C5 or ant-CD20 have been used in some reference centers [18] [19] [20].

No report of ECAA caused by CAPS was found in the literature.

It remains evident that ECAA related morbidity and mortality caused by CAPS are influenced by a quick and correct diagnosis.

\section{Conflicts of Interest}

The authors declare no conflicts of interest regarding the publication of this paper.

\section{References}

[1] El-Sabrout, R. and Cooley, D.A. (2000) Extracranial Carotid Artery Aneurysms: Texas Heart Institute Experience. Journal of Vascular Surgery, 31, 702-712. https://doi.org/10.1067/mva.2000.104101

[2] Attigah, N., Külkens, S., Zausig, N., Hansmann, J., Ringleb, P., et al. (2009) Surgical Therapy of Extracranial Carotid Artery Aneurysms: Long-Term Results over a 24-Year Period. European Journal of Vascular and Endovascular Surgery, 37, 127-133. https://doi.org/10.1016/j.ejvs.2008.10.020

[3] Park, K.M. and Kim, D.I. (2016) Bilateral Extracranial Carotid Artery Aneurysms Treated by Staged Surgical Repair. EJVES Short Reports, 36, 13-15. https://doi.org/10.1016/j.ejvssr.2016.11.002

[4] Jennette, J.C., Falk, R.J., Bacon, P.A., Basu, N., Cid, M.C., Ferrario, F., et al. (2013) 2012 Revised International Chapel Hill Consensus Conference Nomenclature of Vasculitides. Arthritis \& Rheumatism, 65, 1-11. https://doi.org/10.1002/art.37715

[5] Bezerra, A.S., Polimanti, A.C., Oliveira, R.A., Fürst, R.V.C., Criado, P.R. and Corrêa, J.A. (2020) Early Diagnosis and Treatment of Leukocytoclastic Vasculitis: Case Report. Jornal Vascular Brasileiro, 19, Article ID: e20180072. 
https://doi.org/10.1590/1677-5449.190093

[6] Jennette, J.C., Falk, R.J., Andrassy, K., Bacon, P.A., Churg, J., et al. (1994) Nomenclature of Systemic Vasculitides. Proposal of an International Consensus Conference. Arthritis \& Rheumatism, 37, 187-192. https://doi.org/10.1002/art.1780370206

[7] Miyakis, S., Lockshin, M.D., Atsumi, T., Branch, D.W., Brey, L.R., et al. (2006) International Consensus Statement on an Update of the Classification Criteria for Definite Antiphospholipid Syndrome (APS). Journal of Thrombosis and Haemostasis, 4, 295-306. https://doi.org/10.1111/j.1538-7836.2006.01753.x

[8] Cervera, R., Rodríguez-Pintó, I., Colafrancesco, S., Conti, F., Valesini, G., et al. (2014) 14th International Congress on Antiphospholipid Antibodies Task Force Report on Catastrophic Antiphospholipid Syndrome. Autoimmunity Reviews, 13, 699-707. https://doi.org/10.1016/j.autrev.2014.03.002

[9] Bucciarelli, S., Espinosa, G., Cervera, R., Erkan, D., Gómez-Puerta, J.A., et al. (2006) Mortality in the Catastrophic Antiphospholipid Syndrome: Causes of Death and Prognostic Factors in a Series of 250 Patients. Arthritis \& Rheumatism, 54, 2568-2576. https://doi.org/10.1002/art.22018

[10] Zuily, S., de Laat, B., Guillemin, F., Kelchtermans, H., Magy-Bertrand, N., et al. (2020) Anti-Domain I $\beta_{2}$-Glycoprotein I Antibodies and Activated Protein C Resistance Predict Thrombosis in Antiphospholipid Syndrome: TAC(I)T Study. The Journal of Applied Laboratory Medicine, 5, 1242-1252. https://doi.org/10.1093/jalm/jfaa072

[11] Bezerra, A.S., Wroclawski, C.K., Lorber, G.R. and Filho, C.C. (2021) Secondary Vasculopathy Due to Catastrophic Antiphospholipid Syndrome. Hematology, Transfusion and Cell Therapy. (In Press) https://doi.org/10.1016/j.htct.2021.09.012

[12] Cervera, R., Piette, J.C., Font, J., Khamstha, M.A., Shoenfeld, Y., et al. (2002) Antiphospholipid Syndrome: Clinical and Immunologic Manifestations and Patterns of Disease Expression in a Cohort of 1,000 Patients. Arthritis \& Rheumatism, 46, 1019 1027. https://doi.org/10.1002/art.10187

[13] Abreu, J.S.F., Santos, A.O., Medeiros, J.N. and Gouvea, C.P. (2018) Models for Releasing the Lupus Anticoagulant Test. Jornal Brasileiro de Patologia e Medicina Laboratorial, 54, 153-157.

[14] Ortel, T.L., Erkan, D. and Kitchens, C.S. (2015) How I Treat Catastrophic Trombotic Syndromes. Blood, 126, 1285-1293. https://doi.org/10.1182/blood-2014-09-551978

[15] Cervera, R. (2010) Update on the Diagnosis, Treatment, and Prognosis of the Catastrophic Antiphospholipid Syndrome. Current Rheumatology Reports, 12, 70-76. https://doi.org/10.1007/s11926-009-0073-6

[16] Zar, T. and Kaplan, A.A. (2008) Predictable Removal of Anticardiolipin Antibody by Therapeutic Plasma Exchange (TPE) in Catastrophic Antiphospholipid Antibody Syndrome (CAPS). Clinical Nephrology, 70, 77-81. https://doi.org/10.5414/CNP70077

[17] Schmidt-Tanguy, A., Voswinkel, J., Henrion, D., Subra, J.F., Loufrani, L., et al. (2013) Antithrombotic Effects of Hydroxychloroquine in Primary Antiphospholipid Syndrome Patients. Journal of Thrombosis and Haemostasis, 11, 1927-1929. https://doi.org/10.1111/jth.12363

[18] Berman, H., Rodríguez-Pintó, I., Cervera, R., Morel, N., Costedoat-Chalumeau, N., et al. (2013) Rituximab Use in the Catastrophic Antiphospholipid Syndrome: Descriptive Analysis of the CAPS Registry Patients Receiving Rituximab. Autoimmunity Reviews, 12, 1085-1090. https://doi.org/10.1016/j.autrev.2013.05.004

[19] Shapira, I., Andrade, D., Allen, S.L. and Salmon, J.E. (2012) Brief Report: Induction of Sustained Remission in Recurrent Catastrophic Antiphospholipid Syndrome via Inhibition of Terminal Complement with Eculizumab. Arthritis \& Rheumatism, 64, 
2719-2723. https://doi.org/10.1002/art.34440

[20] Erkan, D. and Salmon, J.E. (2016) The Role of Complement Inhibition in Thrombotic Angiopathies and Antiphospholipid Syndrome. Turkish Journal of Haematology, 33, 1-7. https://doi.org/10.4274/tjh.2015.0197

\section{Abbreviations}

APS: Antiphospholipid Syndrome;

CHCC: Chapel Hill Consensus Conference;

CAPS: Catastrophic Antiphospholipid Syndrome;

ECAA: Extracranial Carotid Artery Aneurysm;

IVIG: Intravenous Immunoglobulins;

OAPS: Obstetric Antiphospholipid Syndrome;

PAN: Polyarteritis Nodosa;

TAPS: Thrombotic Antiphospholipid Syndrome.

g/day: grams per day;

$\mathrm{mg} / \mathrm{dl}$ : miligrams per deciliter;

$\mathrm{mg} / \mathrm{kg} /$ day: miligrams per kilo per day;

mmHg: milimeters of Mercury;

$\mathrm{mmol} / \mathrm{l}$ : milimole per liter. 